\title{
Health Related Quality of Life of Pregnant Women and Associated Factors: An Integrative Review
}

\author{
Cinthia Gondim Pereira Calou1,2, Ana Karina Bezerra Pinheiro², \\ Régia Christina Moura Barbosa Castro², Mirna Fontenele de Oliveira², \\ Priscila de Souza Aquino², Franz Janco Antezana ${ }^{2}$ \\ ${ }^{1}$ Departamento de Enfermagen, Universidade Regional do Cariri, Ceará, Brasil \\ ${ }^{2}$ Department of Nursing, Federal University of Ceará, Fortaleza, Brazil \\ Email: cinthiacalou@hotmail.com
}

Received 30 July 2014; revised 15 September 2014; accepted 30 September 2014

Copyright (C) 2014 by authors and Scientific Research Publishing Inc.

This work is licensed under the Creative Commons Attribution International License (CC BY). http://creativecommons.org/licenses/by/4.0/

c) (i) Open Access

\begin{abstract}
Objective: The objectives were to characterize the scientific production on Health-Related Quality of Life of pregnant women, identify the areas that are most affected during pregnancy and puerperal period and identify the instruments used to assess quality of life related to health in pregnant women. Methods: For the integrative review, 11 articles published from 2006 to 2013 in the PUBMED, MEDLINE, CINAHL, SCOPUS and SCIELO were selected. Result: Data showed scarce publication from nursing professionals, prevalence of non-experimental studies conducted mainly in Brazil. The most commonly instruments used were the WHOQOL-BREF and SF-12. The presence of pain, nausea and vomiting, depression, low education, younger age and absence of partner negatively affect the quality of life of pregnant women. Practicing physical activity and being socially supported during pregnancy favour a better quality of life. In the domain of social relations, sexuality was the only affected facet. Conclusion: Gaps in the level of evidence considered weak were identified. We suggest bigger role of nurses in research on the subject so that there will be the development of effective interventions to support nursing practice and ensure quality care and consequently improve the quality of life of women in pregnancy and childbirth.
\end{abstract}

\section{Keywords}

Prenatal, Quality of Life, Nursing

How to cite this paper: Calou, C.G.P., Pinheiro, A.K.B., Castro, R.C.M.B., de Oliveira, M.F., de Souza Aquino, P. and Antezana, F.J. (2014) Health Related Quality of Life of Pregnant Women and Associated Factors: An Integrative Review. Health, 6, 2375-2387. http://dx.doi.org/10.4236/health.2014.618273 


\section{Introduction}

Pregnancy reflects a normal process in the female life cycle. In particular, the physiological changes that occur during pregnancy affecting the biochemistry and anatomy of organs and systems should be considered, and may aggravate pre-existing morbidities or produce symptoms that affect the quality of life [1].

The complexity of the changes caused by pregnancy is restricted to not only the physical variables, but also psychological and social variables, which can be reflected in the postnatal period and impact on quality of life of these women. Few women live the cycle of pregnancy and childbirth without encountering real or potential problems [2]. Thus, the prenatal period should be also a moment of preparation of the woman for the childbirth and maternity.

In this perspective, the prenatal appointments are considered a fundamental assistance to women, children and family for allowing regular monitoring that not only detect the physical health disorders, but also provide a humanized and extended care, to promote support in the development of the new role of mother, and thus lessen the damage that could affect one's functional state and overall well-being. According to Symon et al. [3], a focus on maternal quality of life is necessary because one of the goals of prenatal care is the support and encouragement of healthy psychosocial adjustment, plus a look at the sociological aspects and the influences that pregnancy can result in a family.

Although the importance of the gestational period has been recognized in recent years, a better investigation of the aspects that influence the quality of life (QL) of women during this phase may be beneficial to adopt strategies to promote maternal health. Information on the changes experienced by pregnant women in the physical, psychological and social domains is still limited, which suggests that the quality of life of the pregnant woman and the aspects that can change it is a topic that deserves more attention [4] [5].

Studies on quality of life (QL) have increased in the last years, both in the national and international literature, becoming a theme highlighted in today's society [6]. The World Health Organization has defined it as the individual's perception of their position in life in the context of culture and value systems in which they live and in relation to their goals, expectations, standards and concerns [7].

In health there is a tendency to use the term Quality of Life Related to Health (QLRH), which considers aspects related to diseases, disorders and the needs of therapeutic interventions [8]. This definition is more specific; it offers a holistic view that encompasses physical, psychological and social aspects, which are fundamental domains to analyze quality of life [9].

Conducting research on Quality of Life Related to Health (QLRH) in pregnant women becomes important to identify the affected domains and to plan nursing interventions, in order to ameliorate their quality of life, as well as stimulating the empowerment of women before some transformations, sometimes taken for granted, but which negatively affect your quality of life.

Brazil has signed internal and external commitments to improving the quality of health care provided to pregnant women in order to reduce maternal and infant mortality. Promoting woman health for the majority of our population is one of the expected outcomes. So, increasing knowledge of the quality of life maternal determinants for this outcome is an important strategy.

In addition, the effectiveness of nursing interventions to improve the HRQL of women during pregnancy has been reported in international studies and systematic reviews [10].

Thus, it is noticed that the importance of investigating the scientific literature on the main domains can affect the quality of life related to the health of pregnant women, contributing to the deepening of the theme and possibly to support health interventions capable to facilitate a comprehensive and humanized care to the woman.

The guiding question of the study was: "What areas are affected in the quality of life related to health in pregnant women?" So, the study aimed to characterize the scientific production on quality of life related to pregnant women health, identify the areas affected during the pregnancy and puerperal period and identify which instruments are used to evaluate the QLRH in pregnant women. To achieve such goals, an integrative literature review was used, based on evidence-based practice, providing a synthesis of knowledge of the topic investigated.

\section{Methods}

It was performed a qualitative systematic review of articles about quality of life related to pregnant women health and which instruments are used to evaluate the QLRH in pregnant women that was published in electronic database previously select. 
The integrative review is also considered a valuable part of creating and organizing a body of literature, and should have the same levels of clarity, rigor and replication of the primary research process [8].

This method allows previous researches to be summarized and conclusions drawn, considering the design of the studies evaluated, and allowing the synthesis and analysis of scientific knowledge of the topic investigated [11].

To develop this integrative review by the proposal of was chosen in which the following steps are established: 1) identification of the hypothesis or guiding question - is the development of a problematic by the researcher in a clear and objective manner, followed by the search for descriptors or keywords; 2) selection of sample-determining the criteria for inclusion and exclusion, when establishing the transparency to provide depth, quality and reliability in the selection; 3) categorization of studies - defined as the extraction of information with the objective of the revised to summarize and organize items such information; 4) studies evaluation-the analysis of the extracted data should be critically; 5) results discussion and interpretation-moment that the main results are compared and reasoned with the theoretical knowledge and assessment as to its applicability; 6) presentation of the integrative review and synthesis of knowledge-must include the information of each article briefly revised and systematized manner demonstrating the evidence found [12].

It was conducted a search in the literature through the online database of the PUBMED, MEDLINE, CINAHL, SCOPUS and SCIELO, in August 2014, by limiting itself to articles published between January 1, 2006 to December 31, 2013. The reason to limit the time was because we intended find the most current evidence. Initially, the following descriptors were used, in English, for searching in the PUBMED, MEDLINE (Medical Literature Analysis and Retrievel System On-Line, CINAHL (Cumulative Index to Nursing \& Allied Health Literature), SCOPUS, SCIELO (Scientific Eletronic Library On-Line) and COCHRANE:

\#1) "quality of life" (medical subject headings [MeSH term, in English]);

\#2) "pregnancy" (MeSH term); and

\#3) "prenatal care" (MeSH term).

After, the similar procedure was performed, with the following descriptors in Portuguese, for searching in the LILACS (Literatura Latino-Americana e do Caribe em Ciências da Saúde):

\#1) "qualidade de vida" (Descriptors in Health Sciences [DeCS term, in Portuguese]);

\#2) "gravidez" (DeCS term); and

\#3) “cuidado pré-natal” (DeCS term).

The following searches were performed: \#1 AND \#2, \#3. The articles found by using this strategy were reviewed on two separate occasions, for two blind researchers, in order to ensure the adequacy of the sample.

The analysis of articles followed the inclusion and exclusion criteria previously established. We included: 1) articles that presented on the abstract at least a combination of the terms established; 2) manuscripts in English, Spanish or Portuguese; 3) studies that addressed QLRH theme in pregnant women; 4) original articles with full text accessible through the Portal de Periódicos CAPES (Coordenação de Aperfeiçoamento de Pessoal de Nível Superior); 5) a virtual library connected to the Brazilian Ministry of education with content restricted to authorized users; and 6) observational (analytical or descriptive, except case report), experimental or quasi-experimental studies, both prospective and retrospective. The exclusion criteria were: 1) other study designs, such as case reports, case series, literature reviews; 2) non-original studies, including editorials, book reviews and letters to the editor.

A flow diagram reflecting the process of literature screening was constructed, as shown in the Figure 1.

In the perspective to summarize and organize the information we used the validated instrument of that identifies the publication title, journal name, volume, number, year of publication, authors, professional formation, country and language, along with the criteria for assessment of QL studies, their methodological characteristics. Data were categorized and discussed according to the objectives of this integrative review [11].

\section{Results and Discussions}

133 studies were identified in the Medline database, which after thorough analysis; it was observed that 7 were suitable for inclusion criteria. In LILACS database was found 4 studies, however 3 did not fit the proposed theme and 1 was found indexed in SciELO concomitantly, no studies to be analyzed. In PubMed database 3 studies were found, of which 2 did not meet the inclusion criteria for not suit the theme and 1 was available in another database. A search in the CINAHL database showed 11 publications; however, only 1 met the inclusion 


\begin{tabular}{|c|c|c|}
\hline \multicolumn{3}{|c|}{ 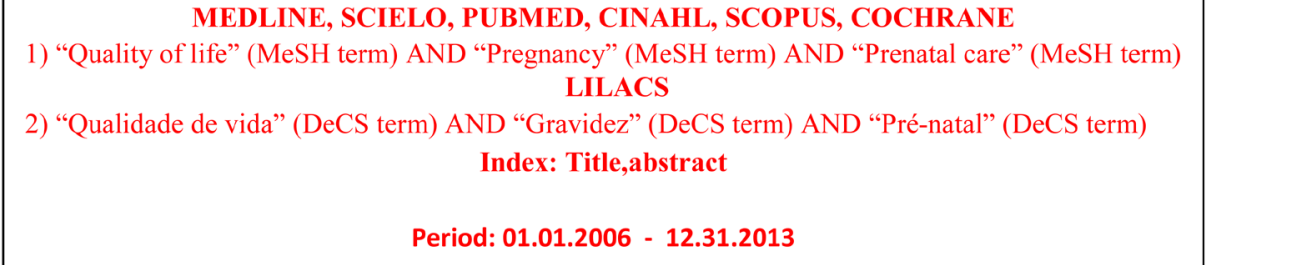 } \\
\hline $\begin{array}{l}\text { Inclusion criteria } \\
\text { 1.References written in English, Spanish } \\
\text { or Portuguese; } \\
\text { 2.Studies that addressed QLRH theme in } \\
\text { pregnant women; } \\
\text { 3.Original articles with accessible full text } \\
\text { online; } \\
\text { 4.Articles that included in the title at least } \\
\text { one combination of terms described in } \\
\text { the search atrategy, and } \\
\text { 5.Observational (analytical or descriptive, } \\
\text { except case report), experimental or } \\
\text { quasi-experimental studies, both } \\
\text { prospective and retrospective }\end{array}$ & $\begin{array}{l}\text { Full-text references } \\
\text { assessed for } \\
\text { eligibility } \\
\quad(\mathrm{n}=11)\end{array}$ & $\begin{array}{l}\text { 328 references excluded after } \\
\text { examining title and abstract } \\
\text { a) Not about QLRH theme in pregnant } \\
\text { women }=302 \text {; } \\
\text { b) Case report }=06 \\
\text { c) Review }=02 \\
\text { d) Brief communication }=01 \\
\text { e) Abstract or Full text not available }=10 \\
\text { f) Repeated articles }=05 \\
\text { g) Editorial }=01 \\
\text { h) Meta-analysis }=01\end{array}$ \\
\hline
\end{tabular}

Figure 1. Flow chart showing study selection for the review. Abbreviations: MEDLINE, medical literature analysis and retrievel system on-line; CINAHL, cumulative index to nursing \& allied health literature; LILACS, literatura Latino-Americana e do caribe em ciências da saúde; SciELO, scientific eletronic library on-line; MeSH, medical subject headings; QLRH, quality of life related to health; DeCS, descriptors in health sciences.

criteria. In SCOPUS database was revealed 11 articles, but after taking into account the inclusion criteria no article was evidenced in this database. The SciELO database, we consider 14 articles, from which only 3 were classified to sample this search. Finally, based on Cochrane 155 studies were identified, but none met the inclusion criteria. Therefore, this integrative review reached a final sample of 11 selected articles.

Concerning the year of publication, there was a predominance of studies on quality of life in pregnant women in the year 2011 (three studies), followed by the years 2008 (two studies) and 2012 (two studies). In 2006, 2009, 2010 and 2013 only one study on the theme was selected for analysis, in 2007 there was none publications, which shows the diversity of production on this theme in the years evaluated (Table 1).

About the authorship of the studies, it was observed that five articles were published by doctors, two studies by physiotherapists, a study by a midwife and two other studies by multidisciplinary teams composed of physicians, pharmacists, physiotherapists, physical educator and social science professional, one study did not determine the formation of the author. Based on these results, it is reinforced the scarcity of publications on quality of life related to health in pregnant women written by nurses (Table 1).

The highest incidence of publication was in the An International Journal of Obstetrics and Gynaecology, Revista Brasileira de Ginecologia Obstetrícia and Midwifery two studies each. The others journals: Reproductive Health, Journal of Physiotherapy, American Journal of Obstetrics \& Gynecology, Maternal and Child Health Journal and Revista Dor, each had one study (Table 1).

Regarding the methodological design, seven studies were descriptive, cross-sectional, non-experimental and had LoE 6, two studies were experimental with randomized clinical trial, controlled with level of evidence 2, a study was characterized by being quasi-experimental; and another study was the cohort, quantitative, longitudinal and prospective. It is considered that few studies provide strong evidence for clinical application (Table 2).

Regarding the country of origin five studies based in Brazil was identified, two studies in the United States and one in each of the following countries: China, Colombia, Canada and United Kingdom. As for the language, 
Table 1. Description of studies included in the integrative review, according to the authors, database, authors formation, journal and year of publication.

No. Authors $\quad \begin{gathered}\text { Data } \\ \text { base }\end{gathered} \quad \begin{gathered}\text { Authors } \\ \text { formation }\end{gathered} \quad$ Journal $\quad$ Sample size $\begin{gathered}\text { Year of } \\ \text { publication }\end{gathered} \quad$ Summary

Nascimento

S.L., Surita

01 F.G., Parpinelli

1 M.A., Siani S.,

Pinto e Silva

J.L. [13]
An

International Eighty-two

Journal of pregnant

Obstetrics and women

Gynaecology

2011

The study showed that $47 \%$ of pregnant women had weight gains above the recommended limit, compared with $57 \%$ of women in the control group. There was no difference in gestational weight gain between the groups. Overweight pregnant women who exercised gained less weight during the entire pregnancy and after entry into the study compared with women in the control group. Arterial blood pressure was similar between the groups over time. There was no difference in perinatal outcome or QoL.

The study evaluated the relationship of regular practice of gymnastics with the quality of life. The vast majority of the participants felt that the practice of gymnastics had benefited in some way. QoL scores were found to be high in both groups during follow-up. There was no association between QOL and practice exercises.

Pregnant women who were younger, single, divorced, separated or cohabiting, had a lower level of education, worked long hours Lau Y., Doctors, Thirty-five in Osis M.J., Cecatti J.G.,

Baciuk E.P. Cavalcante S.R. social science Reprod group and thirty-one in the experimental group.

1151 of pregnant women in the 03 Yin L. [15]

Medline Not identified Midwifery second trimester of pregnancy.

Arizabaleta

A.V.M., Buitrago L.O.

04 Plata A.C.A., Escudero M.M., Ramírez-Vélez Medline Physiotherapists Journal of $\quad \begin{aligned} & \text { Fifty } \\ & \text { nulliparous }\end{aligned}$ Physiotherapy pregnan women R. [16]

Lacasse A., Rey E.,

05 Ferreira E., Morin C., Bérard A. [17]
Medline Pharmacists and doctors International 507 Journal of pregnant Obstetrics and women Gynaecology o had an unplanned pregnancy with late initiation of antenatal care or poor physical or mental health-related quality of life had higher levels of perceived stress.

Fifty women completed the study. After the 3-month intervention, the experimental group had improved their health-related quality of

life more than the control group in the physical component summary of the questionnaire by 6 points, the physical function domain, the bodily pain domain and the general health domain.

Of the 367 pregnant women included in the study, 78.5\% reported nausea and vomiting in the first trimester of pregnancy. The presence of these symptoms was significantly associated with lower quality of life assessed by the SF-12.

The interviews lasted for 15 - 25 mins and none of the women found the MGI difficult to complete. Face validity were good;
35 women (20 nulliparous

06 Symon A.G. Medline Midwife
Midwifery and 15 parous) in the third trimester of pregnancy formally, but the MGI scores and the GHQ-30 scores were well correlated. While some comment categories were universally positive ("looking for ward to baby", "relationship with partner") and others were universally negative ("tiredness”, "aches and pains"), other categories were mixed ("social life”, “work”). 


\section{Continued}

Nicholson W.K., Setse R.

07 Hill-Briggs F., Medline Doctors Strobino D.,

Powe N.R. [19]

Setse R., Grogan R., Pham L.,

$08 \begin{aligned} & \text { Cooper L.A., Cinahl Doctors } \\ & \text { Strobino D., }\end{aligned}$

Nicholson W.K.

[20]

Gomes M.R.A., Araújo R.C.,

09 Lima A.S., Scielo Physiotherapists Rev Dor Pitangui A.C.R. [21]

Matern. Chilth J.

200 women

receiving

prenatal care

2009

21 pregnant

women

between the

1st and 3rd

quarter

gestational

Purim K.S.M.,

10 Avelar M.F.S [22]

Scielo Doctors
Rev Bras

Ginecol

Obstret
109 postpartum

women
The study sample was $49 \%$ African

American, $38 \%$ white, and $11 \%$ Asian. The prevalence of depressive symptoms was $15 \%$. Women with depressive symptoms had significantly lower health-related quality of life scores in all domains except physical functioning.

The proportion of women with depressive symptoms was $15 \%, 14 \%$, and $30 \%$ in the first, second and third trimesters, respectively, and $9 \%$ after delivery. Women who became depressed had scores lower in the second and third trimesters.

Analyzed 95.23\% of pregnant women reported low back pain during pregnancy, and $71.43 \%$ had it prior to pregnancy. The most pregnant women, $57.14 \%$ reported feeling pain lasting longer than 60 minutes. The combination of pain with lumbar posterior pelvic pain was observed in $66.65 \%$ of pregnant women, and $28.58 \%$ were only low back pain.

Predominant white women, youth and housewives. The majority (80\%) remained exposed to the sun for 1 - 2 hours per day and, of these, $72 \%$ did not apply sunscreen claiming lack of habit. Information during the pre-natal about the risks of sun exposure was reported by $34 \%$ of postpartum women. There was a trend toward a significant association between prenatal guidance and daily use of sunscreen. About $20 \%$ of postpartum women had melasma. The mean score of MELASQoL-PB (25) showed negative impact on quality of life of these patients.

Most women (64.8\%) achieved the QS-F "excellent" and 58.8\% rated their quality of life as "good". Indicated that they were satisfied with the sex lives $35.3 \%$, and $15.7 \%$ were very satisfied.
Ferreira D.Q.

Nakamura M.U., Souza E.,

11 Mariani Neto C., Scielo Doctors
Rev Bras

Ginecol

51 pregnant

Obstret
Santana T.G.M. Abdo C.H.N.

[23]

eight publications were found in the English language and three in Portuguese language. Two of the English publications were originated in Brazil (Table 2).

We can notice that 9 studies did not define QLRH, since it dealt with a subjective and multidimensional concept [9]. However, defining this concept is of paramount importance and correlates it with the situation of the population investigated, since the theme quality of life is increasingly growing. Similar to the present study data were verified who observed that the definition of the term quality of life was rarely reported in review articles they had surveyed, pointing gaps about the importance of this concept. On the validation of the instrument 10 reported having been validated and 1 did not specify [8] [9] (Table 3).

On the use of instruments that measure QLHR, five studies used a single type of instrument; five have opted to use a combination of two instruments and one study did not adopt any instrument. From the instruments used, three were generic, as: WHOQOL-Bref, Short Form-36 Health Survey (SF-36) and the Short Form-12 Health Survey (SF-12); and five instruments were specific: The Mother Generated Index (MGI), Melasma Quality of 
Table 2. Description of studies included in the integrative review according to the study design, level of evidence, country of origin and language.

\begin{tabular}{|c|c|c|c|c|}
\hline No. & Research design & Level of evidences & Country of origin & Idiom \\
\hline 01 & $\begin{array}{l}\text { Experimental, randomized controlled trial, quantitative, longitudinal, } \\
\text { prospective study }\end{array}$ & 2 & Brazil & English \\
\hline 02 & $\begin{array}{l}\text { Experimental, randomized controlled trial, quantitative, longitudinal, } \\
\text { prospective study }\end{array}$ & 2 & Brazil & English \\
\hline 03 & Descriptive non-experimental, exploratory, quantitative, cross study & 6 & China & English \\
\hline 04 & Quasi-experimental, quantitative, longitudinal, prospective & 3 & Colombia & English \\
\hline 05 & Quantitative, cross-sectional, prospective, observational study & 6 & Canada & English \\
\hline 06 & Descriptive non-experimental, exploratory, quantitative, cross study & 6 & United Kingdom & English \\
\hline 07 & Descriptive non-experimental, exploratory, quantitative, cross study & 6 & USA & English \\
\hline 08 & Cohort, quantitative, longitudinal, prospective study & 4 & USA & English \\
\hline 09 & Descriptive cross-sectional, quantitative study & 6 & Brazil & Portuguese \\
\hline 10 & Descriptive cross-sectional, quantitative study & 6 & Brazil & Portuguese \\
\hline 11 & Descriptive cross-sectional, quantitative study & 6 & Brazil & Portuguese \\
\hline
\end{tabular}

Table 3. Distribution of the studies included in the review according to the definition of quality of Life, instruments used and validation for the study.

\begin{tabular}{cccc}
\hline Study & QV definitions & Instruments & Valid or not \\
\hline 01 & No & WHOQOL-bref & Yes \\
02 & QV geral & WHOQOL-bref & Yes \\
03 & QV geral e QVRS & SF-12 e perceived stress scale (PSS) & Yes \\
04 & No & SF-12 & Yes \\
05 & No & SF-12 e NVP-specific QOL & Yes \\
06 & No & the mother generated index (MGI) & Yes \\
07 & No & SF-36 e CES-D & Yes \\
08 & No & SF-36 e CES-D & Yes \\
09 & No & Did not use & - \\
10 & No & MELASQoL-BP & Yes \\
11 & No & WHOQOL-bref e QS-F & Yes \\
\hline
\end{tabular}

Life Scale (MELASQoL-BP), Perceived Stress Scale (PSS), NVP-Specific QoL, Centro de Epidemiologia de Estudos de Depressão (CES-D). As presented in Table 3, it was found that five studies used simultaneously a generic instrument and another specific to measure QL.

Instruments that measure QLRH can be classified into generic when applied to any population and any pathological process, allowing comparisons between different diseases and their treatments; and specific when they are fit for certain types of health status and disease-population sample [24]. The simultaneous use allows obtaining a higher number of data [25] (Table 3).

Table 3 provides the prevalence in the application of WHOQOL-Bref and of Short Form-12 Health Survey (SF-12). Both instruments are short and quick in the application, allowing evaluation of the physical, psychological, social relation and environment areas, these can be applied to healthy populations or populations with chronic diseases and injuries [26]. 
In order to fulfill the purposes of the research, similar data were grouped in the main affected areas identified in the articles studied, presented in Table 4.

From the identification of the main areas that affect the quality of life of pregnant women, we created the following categories as a way to synthesize the knowledge acquired: life quality related to health and the physical area; psychological area and social area of the health related quality of life of the pregnant women.

\subsection{Physical Area of the HRQL}

In this category, six studies that highlights aspects related to the physical area that affect the quality of life of pregnant women were identified, as: pain and discomfort, nausea and vomiting, fatigue and energy, and capacity for work.

Concerning pain and discomfort, the authors concluded that low back pain was the most reported complaint among pregnant women, and was related to an increase in pre-pregnancy weight and high BMI during pregnancy. The studies state that physical activity configures as a beneficial practice and must be stimulate in this population. Supervised exercises like walking, aerobic activities, stretching, aerobics and relaxation showed better results not only in reducing pain, but on general health [21].

Gestational back pain is a major complaint during pregnancy being considered a symptom of multi factorial origin, moreover, is one of the main complaints during pregnancy, making it responsible for several negative effects on the quality of life of these women [23]. In the study analysed, the average duration of pain was longer than 60 minutes, it may be constant. The afternoon and evening times were evidenced as the period of the most intense feeling of the symptoms, being exacerbated with ambulation or the act of sit down [21].

Another aspects studied that interferes with the physical area of pregnant patients are nausea and vomiting, characterized to be physiological changes mainly present in the first trimester of pregnancy, originating from intense hormonal changes experienced by the maternal organism to maintain design [5]. They promote a significant impact on family life as well as the ability to reduce daily activities, social interactions, stress level and intend to have more children [27] [28]. Variables such as advanced maternal age, severity of symptoms, decision to use non-pharmacological methods, compromise the quality of life of pregnant women with regard not only to the physical area, but the psychological one through the expression of negative feelings and attitudes generating stress. However, advanced gestational ages and the access to health care and medication for relief of symptoms improve the quality of life of the patient [15].

The ability to work was an aspect evaluated within the physical area. Findings indicated aspects that favoured positively, such as the welcoming attitude of the boss and reducing labour activities; in opposition to the pressure to perform the tasks until the last trimester of pregnancy, when other nuisances appear, contributing negatively to quality of life during pregnancy.

\subsection{Psychological Area of the HRQL}

Four studies have examined aspects that interfere in the psychological area of pregnant women, negatively affecting her quality of life, including: stress, depressive symptoms and altered self-image as a result of the appearance of melasma.

In the studies evaluated quality of life of the pregnant women was affected by stress caused by various factors, including age, education, marital status, social support during pregnancy, pregnancy planning and work conditions [19].

Younger age was characterized as a triggering factor of emotional stress, mainly related to the difficulty in adjusting to the role of mother, emotional immaturity, financial dependence and low education. The latter, considered as the later generator of stress, a consequence of the lack of opportunities for better employment and income [15].

\begin{tabular}{cccc}
\hline \multicolumn{4}{l}{ Table 4. Summary of the studies categorized by areas. } \\
\hline Areas & Articles & $\# / \mathbf{n}$ & $\%$ \\
\hline Physical & $1,2,3,4,5,6,7,8,9$ & 6 & 81.8 \\
Psychological/mental & $1,3,4,5,6,7,8,10$ & 4 & 72.7 \\
Social relations & 11 & 1 & 36.4 \\
\hline
\end{tabular}


The level of education was identified in studies as a strong indicator of quality of life, when satisfactory it contributed to a better knowledge about how to live healthy, reducing stress arising from pregnancy [29].

The kind of marital relationship appears to be an influential variable of stress in pregnant women. Not being married negatively influenced the quality of life of women, as well as the absence of predisposing spousal support to isolation and social stigma [30] [31]. It is noticed so that women seek in stable marital relationships such as marriage, the necessary support to overcome the changes imposed by pregnancy.

In this context unplanned pregnancy was perceived as a negative factor that favoured the psychological area. Women whose pregnancies are unplanned may have fewer socioeconomic resources and a greater lack of social support, and may suffer psychosocial stress and pressure. These feelings hinder the fulfilment of the daily responsibilities and acceptance of pregnancy [32].

It is noticed that in various degrees and ways, women in different countries, classes, races, ages and marital status find their reproductive decisions structured in a set of socioeconomic conditions that influence family planning and quality of life.

Working conditions associated with the discomforts of pregnancy generate factors that affect quality of life, as those associated with shorter time to rest and sleep, exposure to risks and difficulties in balancing family and work responsibilities with the maternal role.

It could be perceived that women with higher perceived stress have restrictions on mental and physical QLRH, resulting in a reduced functional status, fatigue, loss of energy, depression, anxiety, limitation in work or activities and performance difficulties. These behaviours may contribute to the rising of problems of physical and mental order with impact also in the social area, underscoring the need for psychosocial therapies [33].

The presence of depressive symptoms during pregnancy has important effects on maternal, fetal and child health, compromising functions of physical and mental areas of the pregnant woman. In this context, changes can be observed in the psychological area of the pregnant woman with different symptoms from sadness to depression.

Depressive symptoms appear predominantly in early pregnancy and suggest the need for measures of effective and efficient screening during the prenatal period. However, former studies using the CES-D3 or other instruments suggest that the prevalence depressive symptoms increase in the third trimester [34] [35]. This high prevalence of depression converges with the results of the study conducted in Baltimore City with pregnant women, that verified a greater number of women with depression during the third trimester of pregnancy, however it points out that regardless of gestational age, the presence of symptoms was associated with worse QLRH, directly affecting the social, emotional role and mental health [19].

Women who became depressed in late pregnancy showed 7 of 8 affected areas of the SF-12: physical functioning, physical role, bodily pain, general health, social functioning, emotional role and mental health. Quite depressed women had lower scores in physical functioning, social functioning and emotional role. Finally, women who remained depressed were shown to be affected on physical area, general health and vitality [20].

As for body image, pregnant women are emotionally affected by the changes that occur in their physical appearance, among these stands out the pigmentary changes such melasma [36] [37].

The melasma causes negative impact on quality of life in pregnant women, mainly for affecting the face and body image, contributing to low self-esteem affecting negatively the relationships in personal life, and professional [38].

When the MELASQoL to evaluate quality of life of postpartum with melasma was applied, the results indicated symptoms ranging from discomfort caused by acne until the appearance of frustration and embarrassment on the part of the women studied.

In short, these aspects should be considered in prenatal care, contributing to psychological well-being during pregnancy.

\subsection{Social Area of the HRQL}

Only one study evaluated sexuality as an aspect of social relationships area; affected by pregnancy, directly interfering with quality of life of pregnant women was found.

Pregnancy marks a process of intense changes directly affecting the lives of women. One of the dimensions that may be affected is the sexuality. Sexual desire during pregnancy can be decreased, and consequently the physiological and psychological changes, including myths and taboos about sex in pregnancy [38]. 
The presence of some disorder in female sexuality, either discontinuation or alteration of any of the stages of sexual response, can result in the emergence of sexual dysfunction, may lie in a greater impact on the quality of life of women, affecting on their self-esteem and interpersonal relationships [39].

In Brazil, two studies have shown that sexual function of Brazilian healthy pregnant was more compromised as approaching the childbirth [40] [41]. Another study compared sexual function between pregnant women with diabetes and healthy pregnant women and found that the prevalence of symptoms of female sexual dysfunction was high in both healthy pregnant women and in those with gestational diabetes mellitus during the third trimester of pregnancy [42].

The study results contemplated in integrative review assessed the association between quality of life and sexual function in pregnant women, and this association proved that it was observed that women who reported poor quality of life also had a final score in the questionnaire QS-F classified as bad. Likewise, the results proved that sexual satisfaction is associated with sexual function, because pregnant women with scores in the QS-F above the cut-off for classification of risk for sexual dysfunction reported being sexually satisfied [23].

\section{Conclusions}

The integrative review enabled the construction of a synthesis of scientific knowledge regarding the areas of the HRQL affected by pregnancy. It was possible to detect gaps in the knowledge produced and analyzed studies were classified as low evidence demonstrating the need for further research with greater methodological rigor.

The most discussed category, i.e. with the highest number of scientific publications was the physical area of the HRQL, depicting points of dissatisfaction as: pain, discomfort, nausea and vomiting, and questions about energy and fatigue related to the ability to the work.

Although the categories on the psychological domain and social relations have been addressed in a smaller number of studies, it does not minimize reflected in its quality of life of pregnant women importance. It might be noted that an affected domain reflects the other, justifying the interconnection of these.

It should be considered in this review the bias, because a period of time was set, reducing the number of localized research. In addition, all indexed articles about quality of life that didn't use that descriptor were not found in the search.

The dissatisfaction revealed by each area pointed shows a shy action of the assistance of the nursing with regard to guidelines that include aspects of QLRH. It is essential that nurses have a qualified listening about the common complaints of pregnancy, valuing this important moment.

\section{References}

[1] Lopes, R.C.S., Prochnow, L.P. and Piccinini, C.A. (2010) Mother's Relationship with Female Support Figures. Psicologia em Estudo, 15, 295-304. http://www.scielo.br/pdf/pe/v15n2/a08v15n2 http://dx.doi.org/10.1590/S1413-73722010000200008

[2] Hill, P.D., Aldag, J.C., Hekel, B., Riner, G. and Bloomfield, P. (2006) Maternal Postpartum Quality of Life Questionnaire. Journal of Nursing Measurement, 14, 205-220. http://dx.doi.org/10.1891/jnm-v14i3a005

[3] Symon, A., Mackay, A. and Ruta, D. (2003) Postnatal Quality of Life Assessment: A Pilot Study Using the Mother Generates Index. Journal of Advanced Nursing, 42, 21-29. http://www.ncbi.nlm.nih.gov/pubmed/12641808 http://dx.doi.org/10.1046/j.1365-2648.2003.02575.x

[4] Escudero-Rivas, R., Carretero, P., Canõ, A., Cruz, M. and Florido, J. (2013) Modifications of Sexual Activity during Uncomplicated Pregnancy: A Prospective Investigation of Spanish Women. Health, 5, 1289-1294. http://www.scirp.org/journal/PaperInformation.aspx?PaperID=35540\#.VBBqD8JdVic http://dx.doi.org/10.4236/health.2013.58175

[5] Mogos, M.F., August, E.M., Salinas-Miranda, A.A., Sultan, D.H. and Salihu, H.M. (2013) A Systematic Review of Quality of Life Measures in Pregnant and Postpartum Mothers. Applied Research in Quality of Life, 8, 219-250. http://www.ncbi.nlm.nih.gov/pmc/articles/PMC3667203/ http://dx.doi.org/10.1007/s11482-012-9188-4

[6] Casarin, S.T., Barboza, M.C.N. and Siqueira, H.C.H. (2010) Quality of Life in Pregnancy: Literature Systematic Review. Journal of Nursing UFPE on Line, 4. http://www.revista.ufpe.br/revistaenfermagem/index.php/revista/article/view/892

[7] The WHOQOL Group (1995) The World Health Organization Quality of Life Assessment (WHOQOL): Position Paper from the World Health Organization. Social Science \& Medicine Journal, 41, 1403-1409. 
http://www.ncbi.nlm.nih.gov/pubmed/8560308

http://dx.doi.org/10.1016/0277-9536(95)00112-K

[8] Nicolussi, A.C. and Sawada, N.O. (2010) Factors That Influence the Quality of Life of Patients with Colon and Rectal Câncer. Acta Paulista de Enfermagem, 23, 125-130. http://www.scielo.br/pdf/ape/v23n1/en_20.pdf http://dx.doi.org/10.1590/S0103-21002010000100020

[9] Zandonai, A.P., Cardozo, F.M.C., Nieto, I.N.G. and Sawada, N.O. (2010) Quality of Life in Cancer Patients: Integrative Review of Latin American Literature. Revista Eletrônica de Enfermagem, 12, 554-561.

http://www.fen.ufg.br/fen_revista/v12/n3/v12n3a20.htm http://dx.doi.org/10.5216/ree.v12i3.6957

[10] Armstrong, K.L. and Morris, J. (2000) Promoting Secure Attachment, Maternal Mood and Child Health in a Vulnerable Population: A Randomized Controlled Trial. Journal of Paediatrics and Child Health, 36, 555-562. http://dx.doi.org/10.1046/j.1440-1754.2000.00591.x

[11] Nicolussi, A.C. (2008) Quality of Life of Patients with Colon and Retal Cancer: Integrative Review. Ph.D. Dissertation, Health School of Nursing of Ribeirão Preto, São Paulo University. http://www.teses.usp.br/teses/disponiveis/22/22132/tde-03092008-111111/pt-br.php

[12] Ganong, L.H. (1987) Integrative Reviews of Nursing Research. Research in Nursing \& Health, 10, 1-11. http://www.ncbi.nlm.nih.gov/pubmed/3644366 http://dx.doi.org/10.1002/nur.4770100103

[13] Nascimento, S.L., Surita, F.G., Parpinelli, M.A., Siani, S. and Pinto e Silva, J.L. (2011) The Effect of an Antenatal Physical Exercise Program on Maternal/Perinatal Outcomes and Quality of Life in Overweight and Obese Pregnant Women: A Randomised Clinical Trial. BJOG: An International Journal of Obstetrics and Gynaecology, 118, 14551463. http://www.ncbi.nlm.nih.gov/pubmed/21895947

[14] Vallim, A.L., Osis, M.J., Cecatti, J.G., Bacuick, E.P., Silveira, C. and Cavalcante, S.R. (2011) Water Exercises and Quality of Life during Pregnancy. Reproductive Health, 8, 14.

http://www.ncbi.nlm.nih.gov/pmc/articles/PMC3113331/ http://dx.doi.org/10.1186/1742-4755-8-14

[15] Lau, Y. and Yin, L. (2011) Maternal, Obstetrics Variables, Perceived Stress and Health-Related Quality of Life among Pregnant Women in Macao, China. Midwifery, 27, 668-673.

http://www.sciencedirect.com/science/article/pii/S0266613810000276 http://dx.doi.org/10.1016/j.midw.2010.02.008

[16] Arizabaleta, A.V.M., Buitrago, L.O., Plata, A.C.A., Escudero, M.M. and Ramírez-Vélez, R. (2010) Aerobic Exercise during Pregnancy Improves Health-Related Quality of Life: A Randomised Trial. Journal of Physiotherapy, 56, 253258. http://www.ncbi.nlm.nih.gov/pubmed/21091415 http://dx.doi.org/10.1016/S1836-9553(10)70008-4

[17] Lacasse, A., Rey, E., Ferreira, E., Morin, C. and Bérard, A. (2008) Nausea and Vomiting of Pregnancy: What about Quality of Life? BJOG: An International Journal of Obstetrics \& Gynaecology, 115, 1484-1493. http://www.ncbi.nlm.nih.gov/pubmed/18752585

[18] Symon, A. (2008) A Review of Mother's Prenatal and Postnatal Quality of Life. Health and Quality of Life Outcomes, 1, 38. http://www.hqlo.com/content/1/1/38

[19] Nicholson, W.K., Setse, R., Hill-Briggs, F., Cooper, L.A., Strobino, D. and Powe, N.R. (2006) Depressive Symptoms and Health-Related Quality of Life in Early Pregnancy. American College of Obstetricians and Gynecologists, 107, 798-806.

http://www.jhsph.edu/research/centers-and-institutes/womens-and-childrens-health-policy-center/publications/Depress SymptEarlyPregnancy.pdf

[20] Setse, R., Grogan, R., Pham, L., Cooper, L.A., Strobino, D., Powe, N.R. and Nicholson, W. (2009) Longitudinal Study of Depression Symptoms and Health-Related Quality of Life during Pregnancy and after Delivery: The Health Status in Pregnancy (HIP) Study. Maternal and Child Health Journal, 13, 577-587.

http://www.ncbi.nlm.nih.gov/pubmed/18931832 http://dx.doi.org/10.1007/s10995-008-0392-7

[21] Gomes, M.R.A., Araújo, R.C., Lima, A.S. and Pitangui, A.C.R. (2013) Gestacional Low Back Pain: Prevalence and Clinical Presentations in a Group of Pregnant Women. Revista Dor, 14, 114-117. http://www.scielo.br/scielo.php?script=sci_arttext\&pid=S1806-00132013000200008

[22] Purim, K.S.M. and Avelar, M.F.S. (2012) Photoprotection, Melasma and Quality of Life in Pregnant Women. Revista Brasileira de Ginecologia e Obstetrícia, 34, 228-234.

http://www.scielo.br/scielo.php?script=sci_arttext\&pid=S0100-72032012000500007 http://dx.doi.org/10.1590/S0100-72032012000500007 
[23] Ferreira, D.Q., Nakamura, M.U., Souza, E., Mariane Neto, C., Ribeiro, M.C., Santana, T.G.M. and Abdo, C.H.N. (2012) Sexual Function and Quality of Life of Low-Risk Pregnant Women. Revista Brasileira de Ginecologia e Obstetrícia, 34, 409-413. http://www.scielo.br/scielo.php?pid=S0100-72032012000900004\&script=sci_arttext http://dx.doi.org/10.1590/S0100-72032012000900004

[24] Zatta, L.T., Pires, D.C.V., Luz, R.A., Correia, S.F., Brito, V.W. and Vasconcelos, P.P. (2009) Nursing National Scientific Production Analysis on the Generic Tool That Evaluates Quality of Life: Literature Review. Journal of Nursing UFPE on Line, 3, 127-132. http://www.revista.ufpe.br/revistaenfermagem/index.php/revista/article/viewFile/300/pdf_874

[25] Kerr, J., Engel, J., Schlesinger-Raab, A., Sauer, H. and Holzel, D. (2003) Doctor-Patient Communication: Results of a Four-Year Prospective Study in Rectal Cancer Patients. Disease of the Colon and Rectum, 46, 1038-1046. http://link.springer.com/article/10.1007/s10350-004-7278-6\#page-1 http://dx.doi.org/10.1007/s10350-004-7278-6

[26] Brazil Health Ministry (2013) Attention to Prenatal Care for Low-Risk. Brazil Health Ministry, Brasília.

[27] Kuo, S.H., Wang, R.H., Tseng, H.C., Jian, S.Y. and Chou, F.H. (2007) A Comparison of Different Severities of Nausea and Vomiting during Pregnancy Relative to Stress, Social Support, and Maternal Adaptation. Journal of Midwifery \& Women's Health, 52, e1-e7. http://www.ncbi.nlm.nih.gov/pubmed/17207743 http://dx.doi.org/10.1016/j.jmwh.2006.10.002

[28] Mazzotta, P., Maltepe, C., Navioz, Y., Magee, L.A. and Koren, G. (2000) Attitudes, Management and Consequences of Nausea and Vomiting of Pregnancy in the United States and Canada. International Journal of Gynaecology \& Obstetrics, 70, 359-365. http://www.ncbi.nlm.nih.gov/pubmed/10967171 http://dx.doi.org/10.1016/S0020-7292(00)00255-1

[29] Jallo, N., Bourguignon, C., Taylor, A.G. and Utz, S.W. (2008) Stress Management during Pregnancy: Designing and Evaluating a Mind-Body Intervention. Family and Community Health, 31, 190-203.

http://www.ncbi.nlm.nih.gov/pubmed/18552600 http://dx.doi.org/10.1097/01.FCH.0000324476.48083.41

[30] Ogunsiji, O. and Wilkes, L. (2004) Managing Family Life While Studying: Single Mothers’ Lived Experience of Being Students in a Nursing Program. Contemporary Nurse, 18, 108-123.

http://www.ncbi.nlm.nih.gov/pubmed/15729803 http://dx.doi.org/10.5172/conu.18.1-2.108

[31] Miller-Lewis, L.R., Wade, T.D. and Lee, C. (2005) Risk Factors for Pregnancy and Childbearing in a Single Young Women: Evidence from the Australian Longitudinal Study on Women's Health. International Journal of Behavioral Development, 29, 292-303. http://jbd.sagepub.com/content/29/4/292.short http://dx.doi.org/10.1177/01650250544000071

[32] Ware, J.E., Kosinski, M., Turner-Bowker, D.M. and Gandek, B. (2005) How to Score Version 2 of the SF-12 Health Survey. Lincoln, R.I., Boston.

[33] Hass, J.S., Jackson, R.A., Fuentes-Afflick, E., Stewart, A.L., Dean, M.L., Brawarsky, P. and Escobar, G.J. (2005) Changes in the Health Status of Women during and after Pregnancy. Journal of General Internal Medicine, 20, 45-51. http://www.ncbi.nlm.nih.gov/pmc/articles/PMC1490030/ http://dx.doi.org/10.1111/j.1525-1497.2004.40097.x

[34] Zayas, L.H., Cunningham, M., McKee, M.D. and Jankowski, K.R. (2002) Depression and Negative Life Events among Pregnant African-American and Hispanic Women. Women's Health Issues, 12, 16-22.

http://www.sciencedirect.com/science/article/pii/S1049386701001384 http://dx.doi.org/10.1016/S1049-3867(01)00138-4

[35] Zanini, M. and Paschoal, L.H.C. (2004) Dermatoses of Pregnancy. Medicina Cutanea Ibero Latino-Americana, 32, 139-150. http://www.ncbi.nlm.nih.gov/pmc/articles/PMC2763729/

[36] Alves, G.F., Nogueira, L.S.C. and Varella, T.C.N. (2005) Dermatology and Pregnancy. Brazilian Annals of Dermatology, 80, 179-186.

[37] Miot, L.D.B., Miot, H.A., Silva, M.G. and Marques, M.E.A. (2009) Physiopathology of Melasma. Brazilian Annals of Dermatology, 84, 623-635.

[38] Corbocioglu, A., Bakir, V.L., Akbayir, O., Cilesiz Goksedef, B.P. and Akca, A. (2012) The Role of Pregnancy Awareness on Female Sexual Function in Early Gestation. Journal of Sexual Medicine, 9, 1897-1903. http://www.ncbi.nlm.nih.gov/pubmed/22524554 http://dx.doi.org/10.1111/j.1743-6109.2012.02740.x

[39] Lima, A.C.L., Dotto, L.M.G. and Mamede, M.V. (2013) Prevalence of Sexual Dysfunction in Primigravidae in Rio Branco, Acre State, Brazil. Cadernos de Saúde Pública, 29, 1544-1554. http://www.scielo.br/scielo.php?script=sci arttext\&pid=S0102-311X2013000800007 
http://dx.doi.org/10.1590/S0102-311X2013001200007

[40] Leite, A.P.L., Moura, E.A., Campos, A.A.S., Souza, E. and Camano, L. (2009) Validation of the Female Sexual Function Index in Brazilian Pregnant Women. Revista Brasileira de Ginecologia e Obstetrícia, 29, 414-419. http://www.scielo.br/scielo.php?pid=S0100-72032007000800003\&script=sci_arttext

[41] Naldoni, L.M., Pazmiño, M.A., Pezzan, P.A., Pereira, S.B., Duarte, G. and Ferreira, C.H. (2011) Evaluation of Sexual Function in Brazilian Pregnant Women. Journal of Sex \& Marital Therapy, 37, 116-129.

http://www.pglocomotor.com.br/images/online/producao_67738_Evaluation_of_sexual_.pdf http://dx.doi.org/10.1080/0092623X.2011.560537

[42] Ribeiro, M.C., Nakamura, M.U., Scanavino, M.T., Torloni, M.R. and Mattar, R. (2012) Female Sexual Function and Gestational Diabetes. Journal of Sexual Medicine, 9, 786-792. http://www.ncbi.nlm.nih.gov/pubmed/22189099 http://dx.doi.org/10.1111/j.1743-6109.2011.02577.x 
Scientific Research Publishing (SCIRP) is one of the largest Open Access journal publishers. It is currently publishing more than 200 open access, online, peer-reviewed journals covering a wide range of academic disciplines. SCIRP serves the worldwide academic communities and contributes to the progress and application of science with its publication.

Other selected journals from SCIRP are listed as below. Submit your manuscript to us via either submit@scirp.org or Online Submission Portal.
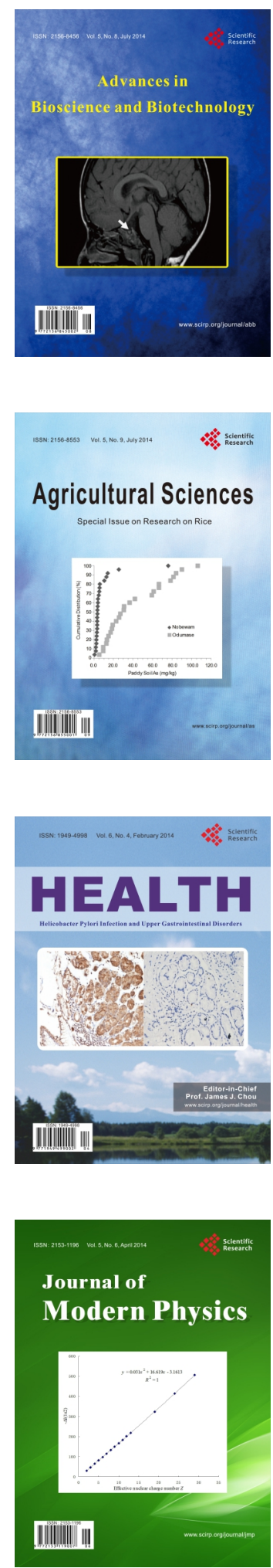
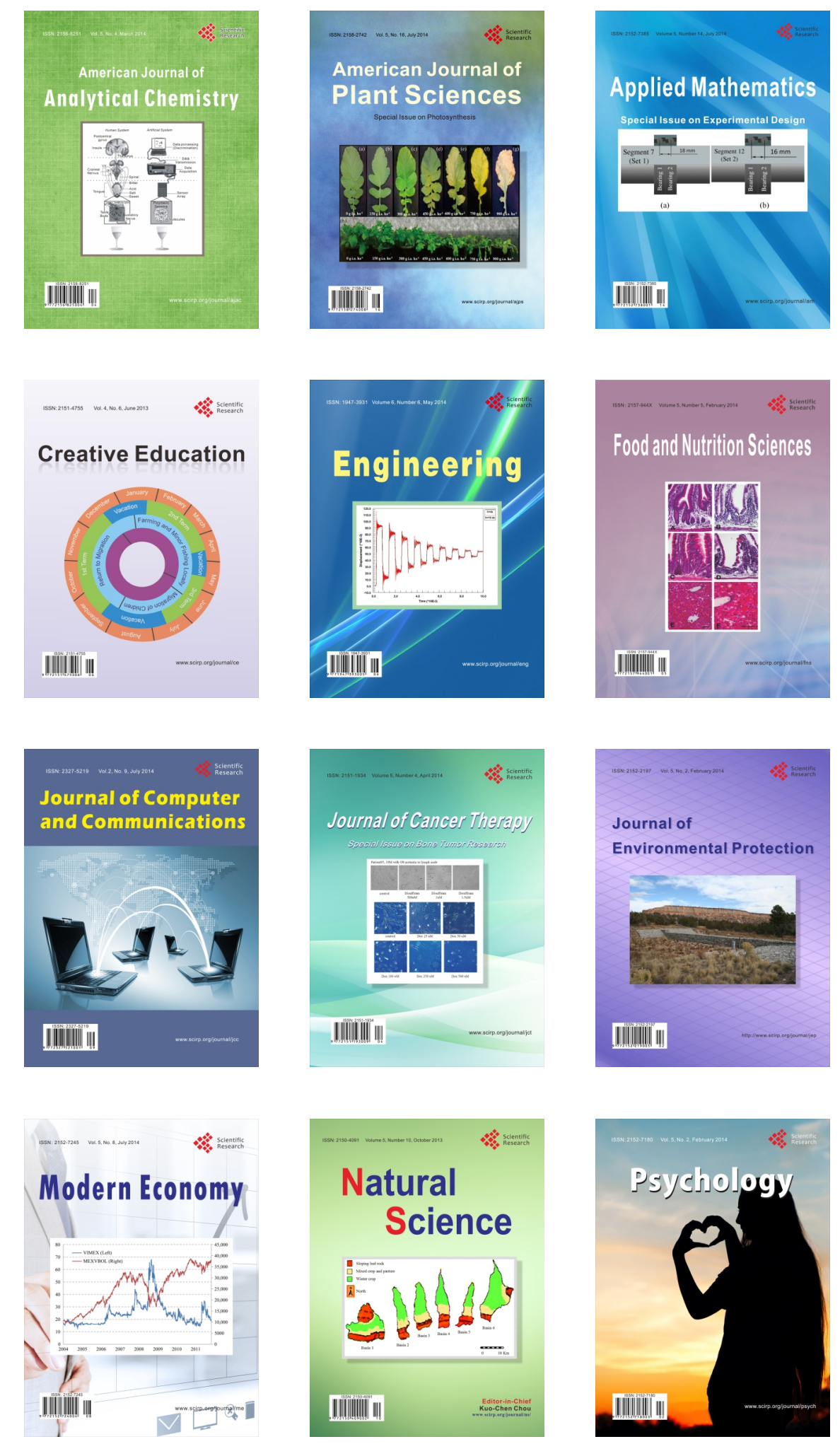